\title{
Management of Oral Submucous Fibrosis with Intralesional Injection of Hyaluronidase and Dexamethasone: A Case Report
}

Thamizhp P Guna ${ }^{1}$, Ramanujam Sathyanarayanan ${ }^{2}$, Rilna Pilavullathil ${ }^{3}$, Nithin J Jude ${ }^{4}$, Raghu Kumaravel ${ }^{5}$, C Selvakumar $^{6}$, S Bharathi ${ }^{7}$

\begin{abstract}
Oral submucous fibrosis (OSMF) is a chronic premalignant condition more common. It occurs mostly due to betel quid chewing. The characteristic feature of OSMF is the progressive hyalinization of the submucosa. Resistance and progression are the factors that attributes to its nature of affecting the entire mucosa. It causes reduction in mouth opening gradually, which can extend to the pharynx. It is a potentially malignant condition causing fibrosis of the connective tissues. Although medical treatment provides only symptomatic, optimal doses of injection with corticosteroids, hyaluronidase, and local anesthesia locally produced significant reduction in the clinical symptoms. This article is to report a case of OSMF, which was treated similarly and had better results than either agents used individually.

Keywords: Dexamethasone, Hyaluronidase, Intralesional injection, Oral submucous fibrosis, Trismus.

Journal of Scientific Dentistry (2020): 10.5005/jp-journals-10083-0924
\end{abstract}

\section{INTRODUCTION}

Oral submucous fibrosis (OSMF) is a precancerous condition due by inflammatory reaction and progressive fibrosis of the submucosa, seen predominantly in Southeast Asia and Indian subcontinent, at a prevalence rate of $0.2 \%-0.5 \%$. Pindborg in 1966 , said OSMF as "an insidious chronic disease affecting any part of the oral cavity and sometimes pharynx. It is associated with juxta-epithelial inflammatory reaction followed by fibroelastic changes in the lamina propria layer, along with epithelial atrophy which leads to rigidity of the oral mucosa proceeding to trismus and difficulty in mouth opening." ${ }^{1}$ Its etiology includes consumption of spicy food, nutritional deficiencies, and areca nut chewing habits. ${ }^{2}$ It involves buccal mucosa, palate, retromolar region, faucial pillars, and pharynx. The characteristic features include burning sensation, blanching, stiffening of the oral mucosa or the oropharynx resulting in trismus, and reduced mouth opening. ${ }^{3}$ Onset of this disease is insidious with a duration of 2-5 years. The malignant transformation rate of OSMF was found to be $7.6 \%{ }^{4}$ Oral submucous fibrosis causes loss of tissue flexibility, enhanced rigidity, reduced salivation, and difficulty in mouth opening. Once the disease has developed, neither regression nor any effective management is a universally accepted phenomena.

\section{Case Description}

A 38-year-old male patient reported to our OPD with the complaint of difficulty in opening the mouth and burning sensation in his oral cavity. Patient had a history of areca nut chewing for 4 years. Patient also had a previous history of OSMF for which he had underwent treatment in a hospital, and then once he was recovering, he resumed his betel nut chewing habit. On examination, reduced mouth opening was persistent for past one month (Figs 1 and 2). On intraoral examination, diffuse blanched appearance was noticed. The buccal mucosa was rubbery and inelastic with vertical band in the posterior molar region and the retromolar region. Patient had a restricted mouth opening of $15 \mathrm{~mm}$. Due to limited
${ }^{1-7}$ Department of Oral and Maxillofacial Surgery, Indira Gandhi Institute of Dental Sciences, Sri Balaji Vidyapeeth, Pillayarkupam, Puducherry, India

Corresponding Author: Thamizhp P Guna, Department of Oral and Maxillofacial Surgery, Indira Gandhi Institute of Dental Sciences, Sri Balaji Vidyapeeth, Puducherry, India, Phone: +91 9486773932, e-mail: drthamizhppozhil9@gmail.com

How to cite this article: Guna TP, Sathyanarayanan R, Pilavullathil R, Jude NJ, Raghu K, Selvakumar C, et al. Management of Oral Submucous Fibrosis with Intralesional Injection of Hyaluronidase and Dexamethasone: A Case Report. J Sci Dent 2020;10(2):41-42.

Source of support: Nil

Conflict of interest: None

mouth opening, patient had a poor oral hygiene status. Based on the history and clinical examination, the patient was provisionally

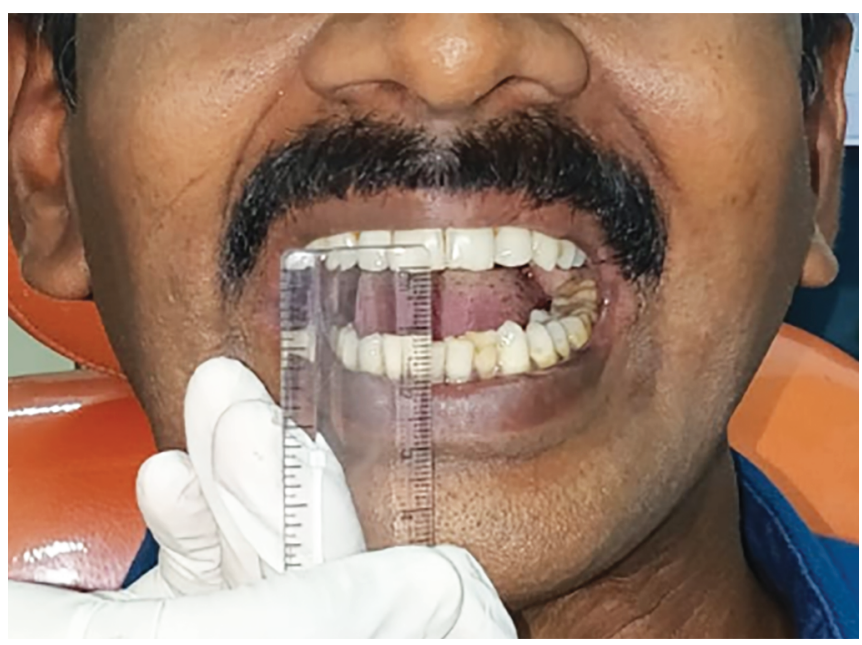

Fig. 1: Reduced mouth opening of less than $15 \mathrm{~mm}$ was seen

(c) The Author(s). 2020 Open Access This article is distributed under the terms of the Creative Commons Attribution 4.0 International License (https://creativecommons. org/licenses/by-nc/4.0/), which permits unrestricted use, distribution, and non-commercial reproduction in any medium, provided you give appropriate credit to the original author(s) and the source, provide a link to the Creative Commons license, and indicate if changes were made. The Creative Commons Public Domain Dedication waiver (http://creativecommons.org/publicdomain/zero/1.0/) applies to the data made available in this article, unless otherwise stated. 


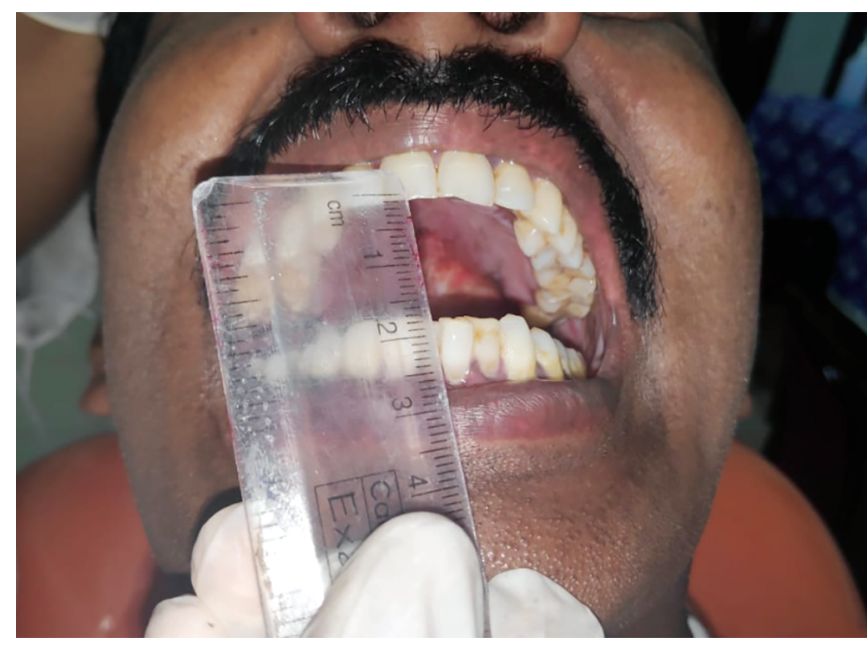

Fig. 2: Mouth opening after forceful mouth opening exercise

diagnosed with grade III OSMF. The patient was advised about his habit and its adverse effects. Patient was explained about the surgical and conservative management protocols after which the patient opted for conservative management since the patient was from a low economic status.

He was treated by triple injection technique intralesionally (dexamethasone $1.5 \mathrm{~mL}$, hyaluronidase $1500 \mathrm{IU}$ with $0.5 \mathrm{~mL}$ lignocaine $\mathrm{HCL}$ ) and injected intralesionally twice in a week for 4 weeks. Adjuvant treatment with pentoxifylline $(400 \mathrm{mg})$ was given 3 times daily to the patient.

Patient was regular in his visits. Patient was advised to quit his deleterious habit and was encouraged to do mouth opening exercises. Patient had a significant increase in mouth opening of $25 \mathrm{~mm}$ and his symptoms reduced significantly. Patient was examined regularly for two months after treatment but did not show up thereafter.

\section{Discussion}

Oral submucous fibrosis, a precancerous condition, reports reveal that it is in existence since the time of Sushruta reported by Schwartz in 1962. Many trials were conducted but no definitive treatment is available. However, intralesional injection of cortisone and hyaluronidase had soon possible relief. ${ }^{2}$ According to Leena et al., patients treated with hyaluronidase had a quick reduction in burning sensation. But combined effect of dexamethasone and hyaluronidase long-term results was more significant than other modalities of management. Dexamethasone has its own advantages and contraindications, but results observed in combination with hyaluronidase are more promising. ${ }^{2}$ Carcinogens from areca nut accumulate below the epithelium, causing reduced vascularity and rapid penetration of carcinogens into the systemic circulation. Conservative treatment (topical steroids, vitamins, antioxidants, and physiotherapy) provides symptomatic relief. ${ }^{5}$ Intralesional injection of placental extracts is a better alternative for hyaluronidase, which acts by biogenic stimulation tissue.

Borle and Borle postulated that intralesional injections of multiple drugs may aggravate the existing condition, which was not found in our study since follow-up was not done. ${ }^{6}$ The condition deteriorates with multiple injections, which was accordingly due to repeated needle stick injury and clinical irritation from medications. ${ }^{7}$

After several clinical trial, glucocorticoids (hydrocortisone, triamcinolone, betamethasone, and dexamethasone) benefited to be minimal effective relieving of symptoms. They impact anti-inflammatory activity and increasing the apoptosis. Steroids are useful in minimizing symptoms or as adjunct. Hyaluronidase, an enzyme, could accelerate OSF by depolymerizing hyaluronic acid, reducing viscosity, and decreasing collagen formation. ${ }^{7}$ Pentoxifylline was used due to its vasodilating properties and ability to decrease the viscosity of blood. ${ }^{8}$ Gupta et al. found that 6 weeks of treatment with tablets containing carotene and vitamin E produced effective outcomes. Also antioxidants like vitamin E and lycopene were also given, which enhanced the results threefold times. ${ }^{9}$ No single drug could effectively manage OSF. The pathogenicity of OSF is obscure. The route of administration is limited..$^{10,11}$

The main treatment modalities are medical, surgical treatment, and physiotherapy. Despite the progress in understanding the pathogenesis, the treatment of OSF cure is significant.

\section{Conclusion}

In OSMF, injection of hyaluronidase with dexamethasone is an effective method of managing it and eliminating the morbidity. It also provides symptomatic relief. Increase in mouth opening with decrease in burning sensation was the most significant outcome of the treatment. It also encouraged the patient to be more regular in his visits and follow our instructions. There were no significant side effects and the result was sustainable. Timingly managing the condition with proper patient education about the consequences will provide a better symptomatic relief rather than a permanent solution. Regular follow-up is also a crucial factor, which our patient skipped once he felt better.

\section{References}

1. Nagaraj T, Okade D, Biswas A, Sahu P, Saxena S. Intralesional injections in oral submucous fibrosis - a series of case reports. J Med, Rad, Pathol Surg 2018;5(5):23-26. DOI: 10.15713/ins.jmrps.145.

2. Jame L, Shetty A, Rishi D, Abraham M. Management of oral submucous fibrosis with injection of hyaluronidase and dexamethasone in grade III oral submucous fibrosis: a retrospective study. J Int Oral Health 2015;7(8):82-85.

3. Chole RH, Patil RK. Drug treatment of oral sub mucous fibrosis - a review. Int J Contempor Med Res 2016;3(4):996-998.

4. Passi D, Bhanot P, Kacker D, Chahal D, Atri M, Panwar Y. Oral submucous fibrosis: Newer proposed classification with critical updates in pathogenesis and management strategies. Natl J Maxillofac Surg 2017;8(2):89-94. DOI: 10.4103/njms.NJMS_32_17.

5. Tekade SA, Chaudhary MS, Tekade SS, Sarode SC, Wanjari SP, Gadbail $A R$, et al. Early stage oral submucous fibrosis is characterized by increased vascularity as opposed to advanced stages. J Clin Diagnos Res 2017;11(5):92-96. DOI: 10.7860/JCDR/2017/25800.9948.

6. BorlE RM, Borle SR. Management of oral submucous fibrosis: a conservative approach. J Oral Maxillofac Surg 1991;49(8):788-791. DOI: 10.1016/0278-2391(91)90002-4.

7. Sinha SN, Jain PK. Intraoral injection of hydrocortisone and placental extract in oral submucous fibrosis. Indian J Otolaryngol 1978;30(2):103.

8. Jiang $X, \mathrm{Hu}$ J. Drug treatment of oral submucous fibrosis: a review of the literature. J Oral Maxillofac Surg 2009;67(7):1510-1515. DOI: 10.1016/j.joms.2008.12.056.

9. Gupta S, Reddy MVR, Harinath BC. Role of oxidative stress and antioxidants in aetiopathogenesis and management of oral submucous fibrosis. Indian J Clin Biochem 2004;19(1):138. DOI: 10.1007/BF02872409.

10. Singh D, Padshetty S. Injection placentrex in the management of oral submucous fibrosis. Int J Mod Sci Eng Technol 2015;2(1):23-30.

11. Warnakulasuriya S, Kerr AR. Oral Submucous fibrosis: a review of the current management and possible directions for novel therapies. Oral Surg, Oral Med, Oral Pathol Oral Radiol 2016;122(2):232-241. DOI: 10.1016/j.0ooo.2016.02.020. 